\title{
Latent Variable Modeling Approach for Assessing Social Impacts of Mine Closure
}

\author{
Mallikarjun Rao Pillalamarry1, Khanindra Pathak ${ }^{2}$ \\ ${ }^{1}$ Department of Mining and Process Engineering, Polytechnic of Namibia, Windhoek, Namibia \\ ${ }^{2}$ Department of Mining Engineering, Indian Institute of Technology, Kharagpur, India \\ Email: mpillalamarry@polytechnic.edu.na
}

Received 2 September 2014; revised 23 October 2014; accepted 2 November 2014

Copyright (C) 2014 by authors and Scientific Research Publishing Inc.

This work is licensed under the Creative Commons Attribution International License (CC BY).

http://creativecommons.org/licenses/by/4.0/

(c) (i) Open Access

\begin{abstract}
Mining stimulates environmental and economic impacts on the neighboring community right from the inception to the closure of its operations. The society in the neighborhood of mining gradually adopts a characteristic life-style that is highly influenced by the mining. In order to sustain the societal development beyond the mine closure, it is necessary to plan post mining activities in the area. Thus, it is essential to predict the impacts of mine closure well before the closure. Many societal and family attributes are affected by mine closure. Impact on these attributes is reflected on the overall quality of life of the neighboring community. There are no adequate indicators and/or methodology available to measure social impacts of mine closure on a neighboring community. This paper made an attempt to develop such methodology to predict the degree of adverse effects of mine closure on the quality of life of neighboring communities using the Structural Equation Modeling (SEM) and the Latent Variables Interaction Model (LVM).
\end{abstract}

\section{Keywords}

Mine Closure, Social Impacts, Structural Equation Modeling, Latent Variable Modeling

\section{Introduction}

Mining is a temporary business and every mining operation is bound to face closure due to resource exhaustion or change in the economics of mining. In some cases, mining may only be suspended for a period of time and the project is placed under care and maintenance. Mine closure ultimately determines what is left behind as a benefit or legacy for future generations. It is important that mine closure is undertaken in a planned and effective manner to avoid hazards and pollution in the future. Unplanned mine closure is associated with safety, environmental and social risks. Such an event can significantly increase the post closure liabilities and economic burden 
on the mining company as well as on the government [1].

Mine closure is a complex issue involving numerous interrelated parameters and influencing factors. These include environment, socio-economics, sale of equipment and assets, water and waste management, etc. Of all the issues, managing the environmental impacts of mining and rehabilitation of mine land after mine closure have been major concerns for governments and mining companies [2]. In most of the countries, mining companies are required to prepare rehabilitation and reclamation plans before starting of mining operations and require financial surety to ensure reclamation [3]-[5]. In some situations, special funding mechanisms are also developed to clear up abandoned mine sites [6] [7]. However, such stringent regulations have not been imposed to address the local social and economic impacts of mine closure. Most of the companies, governments and countries are now recognising that mine closure is much more than the stopping production and decommissioning of the mine. It is increasingly becoming clear that the socio-economic issues of mine closure and the impacts on workers and their families, communities, and the local economy must also be addressed.

\section{Background}

\subsection{Socio Economic Impacts of Mine Closure}

Each stage of mining is associated with specific environmental and social impacts, which are often significant after the closure. At the development stage, mining brings a sudden change in the social structure and supply/ demand scenarios. If a mineral deposit is found below grown-up areas, the mining project calls for rehabilitation of the project affected people (PAP). The site-specific characteristics of mining industry may force the community for relocation. During opening of a mine a large influx of population put strain on the existing services and business structure. Services and infrastructure such as power, sewage and housing are developed to meet increased population which often increase tax burden on the community [8].

On the other hand the impact of mine closure on the community is often severe. Mine closure may result in a sharp decline in their standard of living. Such experiences frequently induce anxiety and stress. The demoralizing effects of mine closure on the wider mining communities are evident in the deterioration of the physical environment, control over young people and participation in the community life. Mine closure brings the loss of community facilities such as recreation grounds and the withdrawal of a range of informal services such as housing maintenance and emergency services, which were provided by the mine management [9]. Figure 1

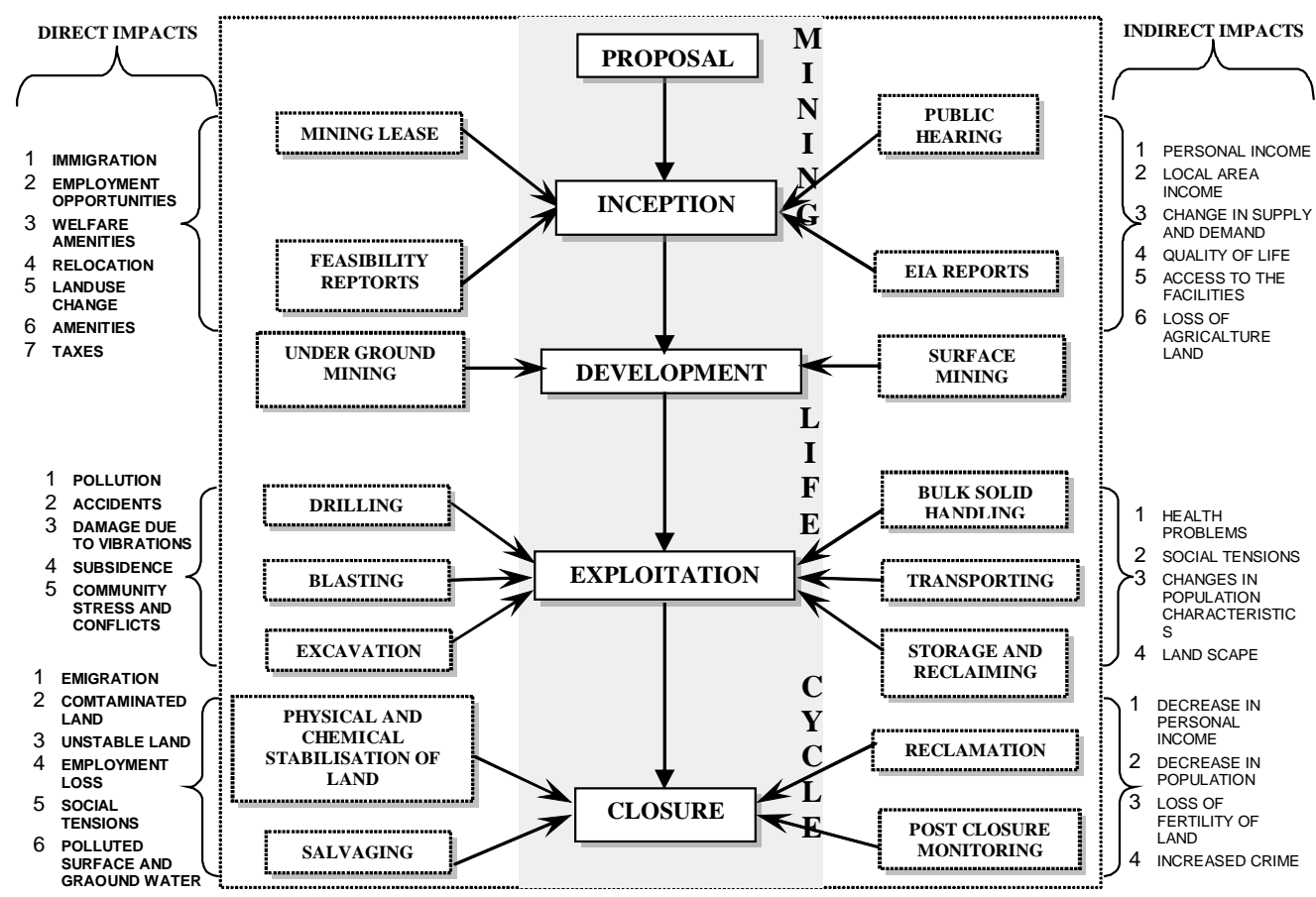

Figure 1. Socio environmental impacts of mining during its life. 
shows impacts at different phases of mining on social and natural environment.

Mining industry plays a major role in the diversified economy of the mining area by providing income, employment and services. In such a context, mine closure will have significant impact on the well-being of the community. Such impacts are exacerbated in developing countries, where alternative economic activities may be more limited, and local government and communities often lack the capacity needed to help and structure a development process that would provide suitable alternatives. In most cases, the community and the mine have developed an interdependent relationship, in terms of employment, services, infrastructure, environment, taxes and royalties. The level of this integration depends on various factors, including the age and location of the mine, the company's approach to the community and region, government policies, and the structure of the local and regional economy. Thus, minimizing mine closure impacts on the community is a complex process and demands participation of different stake holders. It is now established that trilateral consultations are very important to develop effective mine closure program.

In most of the mining regions, a major portion of government tax revenue comes from mining. Thus, there is a natural question that after the mine closure will the government be able to maintain the same level of income. Mine closure may leave a severe impact on the government's ability to sustain its services to its constituents. Similarly, mining communities that received direct income from the mine will see a sharp decline in their income. Thus, it is very important for governments and communities to understand and plan for the eventuality of mine closure. There is a great need to develop non-mining activities and other productive assets in every mining region that will last beyond the life of the mine and generate income for future generations. At the same time, it is typically not possible to replace the economic benefits of the mine completely; major adjustments will likely be required. Figure 2 shows the impacts network of mine closure which shows that there is a perpetual loop which makes the impacts a never ending phenomenon.

In a mining life cycle the issue of mine closure is very crucial and important because the post closure impacts of unplanned closing of a mine are severe for the natural environment and the community [1]. Past abandoned mining sites continue to pose potential threat to human safety, health and environment [10]. The main causes of all the above impacts are loss of employment, labor migration, discontinued service and facilities, loss of community cohesiveness and environmental degradation [9], which have close relation with Quality of Life (QOL) of the communities. Current evidences have suggested that the demographic variables, environmental characteristics, health, leisure, etc. are the potential factors influencing quality of life of the people. There are also other factors such as age, gender, socio-economic status that influence the QOL [11] [12].

\subsection{Quality of Life Approach}

Over the past two decades, Quality of Life (QOL) study created a great interest among many developed and de

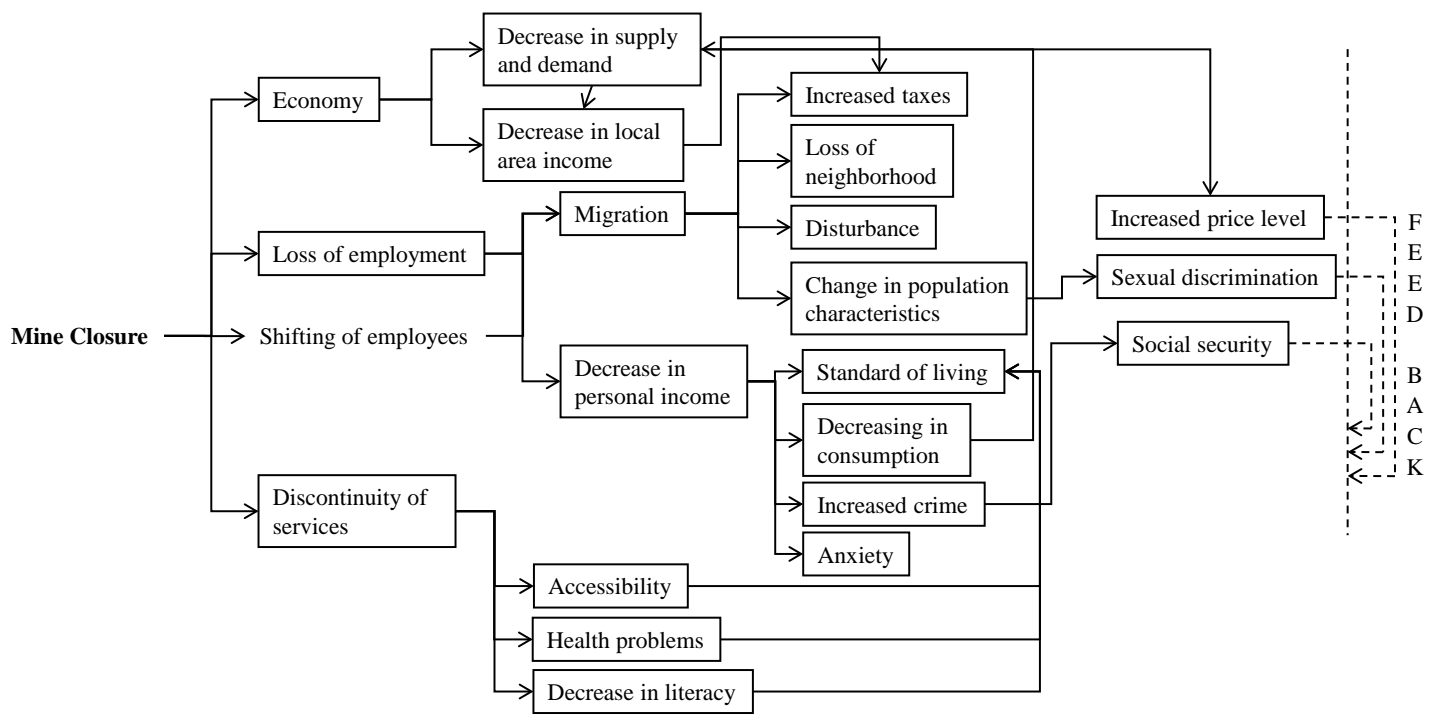

Figure 2. Network of impacts of mine closure. 
veloping nations [13]. Initially, the concept was applied in the field of sociology, but today it is commonly applied to other disciplines such as, health [14] [15], rehabilitation [16] [17], disability studies [18] (Jones et al., 1996) and social services [19], but also in medicine [20], education [21], environment [22] and others. QOL has emerged with as unique concept of setting the goals for services and assessing their impacts on people's dayto-day lives [23]. Most people accept that QOL is an aim for both individual and group of individuals [24]. Although, it is defined in many ways, its objective is to bring together the developmental change in the individual and their identities, nature of circumstances, life style and finally make the people to live quality lives.

In its efforts towards sustainability, the mining industry has used several environmental and economic indicators to assess its performance [25] [26]. In recent years, QOL assessment has proved to be one of the most attractive approaches for this task. Mining activities improve the QOL of the communities living in the nearby areas, since it contributes more in terms of direct and indirect employment, services, local and national economic development [27]-[30]. Such dependency is not same for all the families in the neighborhood so the impacts of mine closure. The basic questions involved in the present investigation are how does mining influences the quality of life of people living nearby, what is going to happen if mining is ceased and how mine closure decisions influence the wellbeing of the neighboring communities.

\subsection{Measuring Quality of Life}

Prior to the 1970s, traditional objective indicators were used to predict human welfare [31]. However, in the early 1970's, social scientists concluded that quality of life was more than a city's financial position or a country's Gross Domestic Product [32] [33]). Factors such as personal income, housing, education, health and recreational facilities, and green space were recognized as contributing to quality of life [33] [34]. By late 1970s and into the 1980s, there was a marked shift in how quality of life was defined and measured. Subjective measures were used to mediate the weakness associated with using objective indicators to measure quality of life [35]. Recent reviews suggested both objective and subjective indicators are necessary to measure quality of life [13] [23] [36] [37].

The subjective nature of quality of life is commonly cited in the health related literature [38] [39]. In contrast, objective factors play an important role in evaluating QOL of city and country level. Objective factors such as income, housing and education impinge on QOL. Lee [40] and Singh \& Chand [41] investigated QOL based on wages and housing expenditure, infrastructure, housing.

Both subjective and objective approaches find predominance in QOL measurement. Some researchers used both objective and subjective measures in assessing QOL of mining communities using the economic, social, political, biophysical, biomedical, and spiritual dimensions [33] [36] [37]. Linga and Subramanya [42], Poston et al. [43], made a qualitative inquiry into individual family quality of life using both subjective and objective dimensions.

The main purpose of the QOL evaluation is to provide a tool for the community development to monitor the living and working conditions of the people and focus on the community actions to improve their health [44]. Whether we measure the quality of life in terms of subjective variables or objective variables, to improve quality life one has to ameliorate objective variables of the Quality of life. For example one person's subjective response of health is poor; to improve his health one has to search for objective variables which are responsible for his poor health. However, objective measures alone cannot give true picture of QOL [36] [37]. Thus, in order to improve Quality of life of a community or group of people, it is necessary to establish a relationship between subjective and objective QOL dimensions. These dimensions near a mining site vary significantly with the performance of the industry as well as with the phase of the mining operations. In the closing phase the situations may worsen if adequate technical measures are not taken at the planning stage.

\section{Methodology}

\subsection{Framework}

The objective of the present work is to develop a quality of life based methodology to quantify societal impacts which would help in mine closure planning. The study attempts to identify the contribution of key socio-economic factors affecting the quality of life of communities living near mining areas. After a thorough review of the available literature it was found that Quality of Life of community depends on number of domains that are 
having direct, indirect or both type of dependencies on the mining activities. However, these domains or factors cannot be easily quantified. The most appropriate method would be to take a site specific methodology. In this study a valid structured questionnaire was used to collect the information from the families and individuals. Both qualitative and quantitative information was obtained through the sampling in selected study areas. Dependencies of the QOL factors and their interrelationships were evaluated using Structural Equation Modeling (SEM). Latent variables scores obtained from SEM model were used for further testing of changed scenario.

To validate the developed methodology a surface mining site engaged in iron ore was selected and necessary information was collected through responses to a valid questionnaire. The datasets so obtained were subsequently analyzed using the SEM software (LISREL) and possible impacts of mine closure in these two areas were estimated. The overall methodology used for the study is illustrated in Figure 3.

Latent Variable Scores (LVS) are individual scores on the latent variables in an estimated structural equation model. These can be obtained for any estimated single group LISREL model. Use of LV scores is to investigate various structural models after establishing the measurement models for the observed variables. One can obtain scores for the latent variables in any estimated LISREL model. However, this needs information about both the

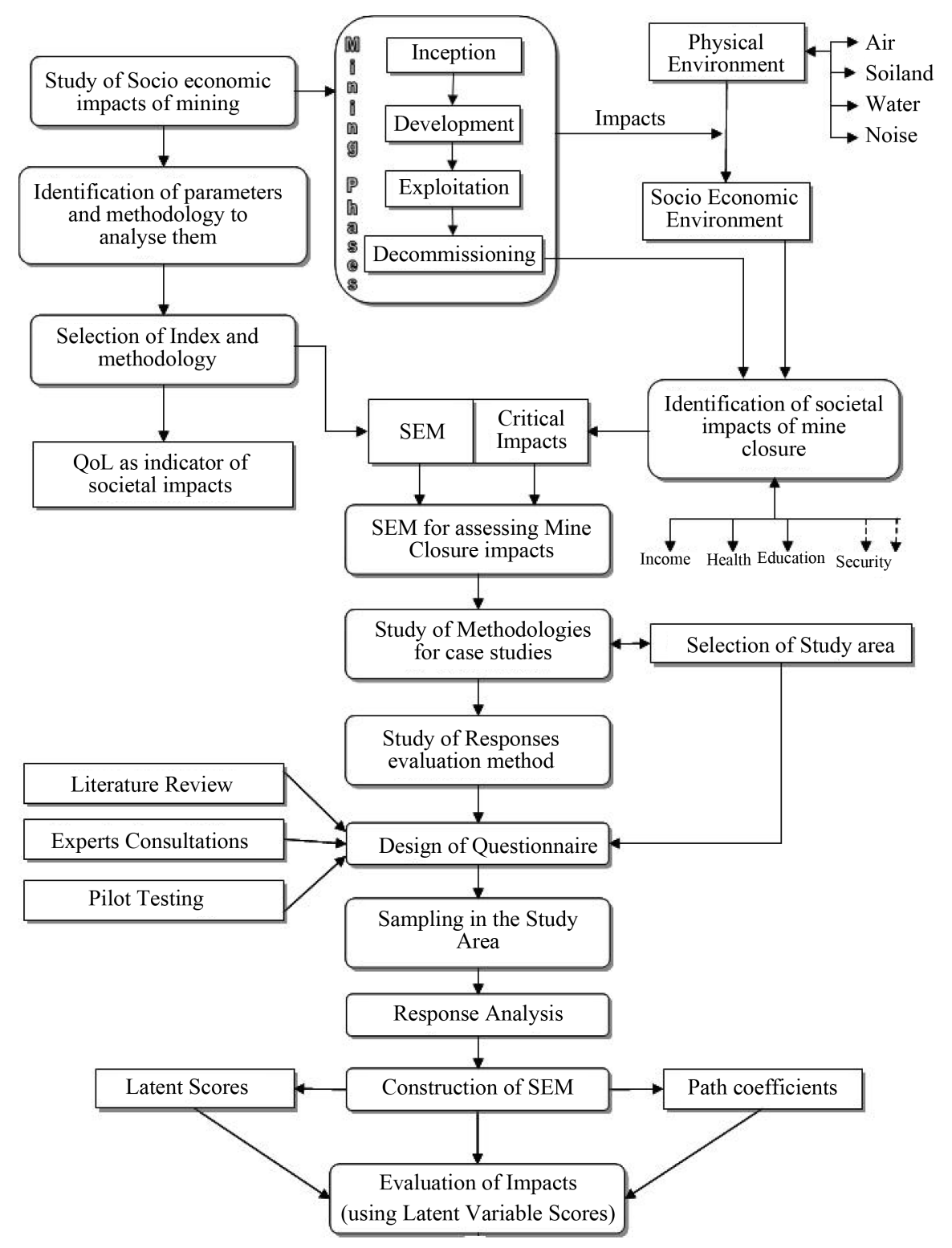

Figure 3. The methodology used for the study. 
raw scores and the estimated model. Joreskog [45] proposed a factor analysis (latent variable score) approach for latent variable interaction modeling. Joreskog's approach is subsequently developed by Schumacker [46]. As the factor scores are influenced by measurement error latent variable score approach holds the promise of being easier to implement and can be applied to more complex latent variable interaction models. Latent scores are unbiased estimates for the latent variables; they have the same means and covariance matrix as the latent variables of the model [46] [47].

\subsection{Conceptual Structural Equation Model}

In the last few decades, scientists offered several alternative approaches to measure quality of life using social indicators such as health and levels of crime, subjective well-being and economic indices. Quality of life is a multidimensional concept [19] and associated with many factors, accounting and identifying all the parameters is rather difficult. Considering the objectives of the study, socio-economic influences of mining, QOL model for a community in the neighborhood of mines was conceptualized as shown in Figure 4.

\section{Results}

\subsection{Study Area and Data Sampling}

One iron open cast mining area is selected for validating the developed methodology for assessing societal impacts of mining. The study area contained two large opencast iron mines currently producing around 7.8 million tonnes per year. Entire mining operations have around 692 full-time employees, of which 50\% of the employees mainly live in the nearby town and remaining live in villages that are accessible by road from the mine.

The sampling frame for the study included the villages in the core zone of the mining area $(5 \mathrm{~km}$ distance

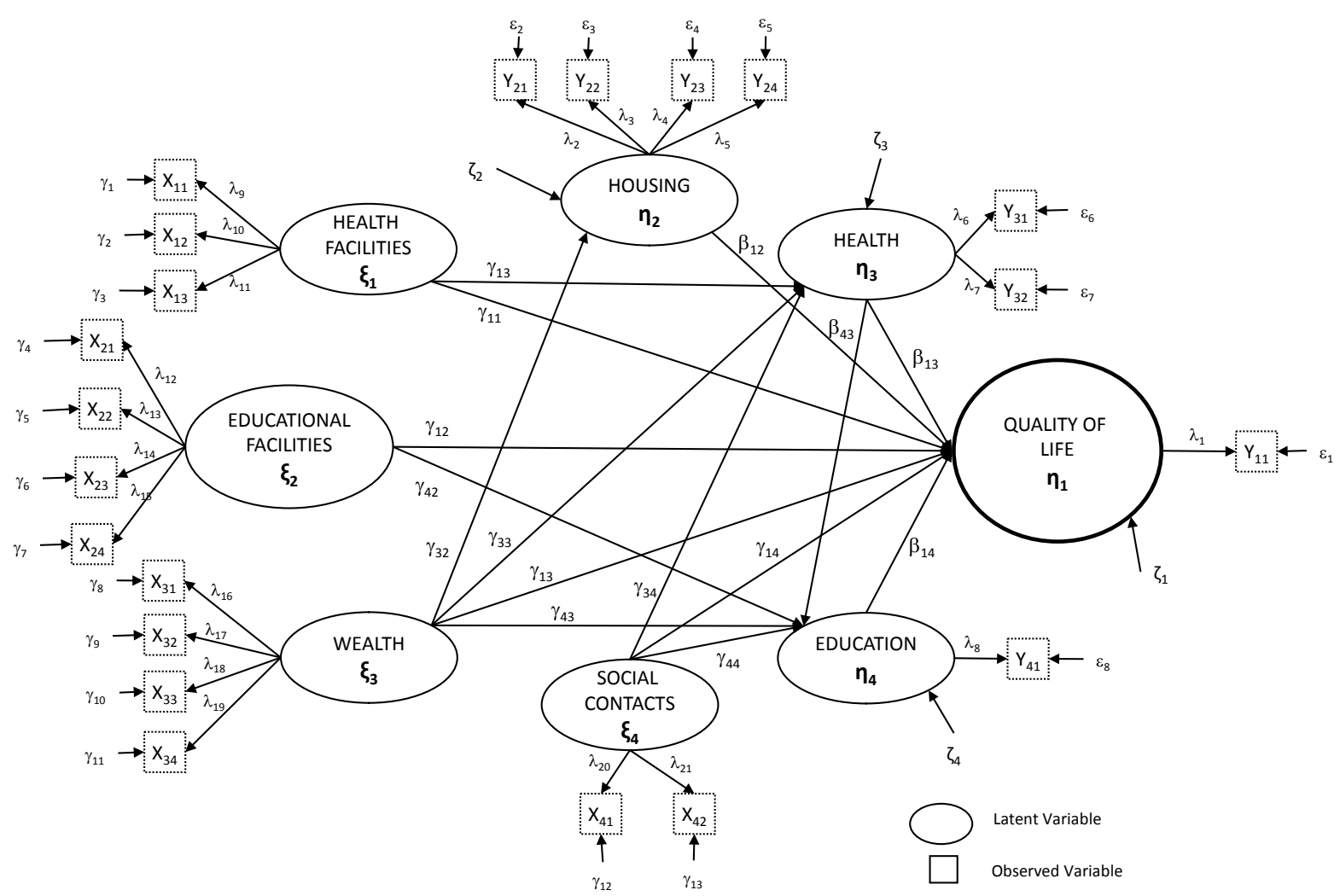

NOTE: $\mathrm{Y}_{11}=$ Subjective QOL, $\mathrm{Y}_{21}=$ Spaciousness, $\mathrm{Y}_{22}=$ Room/Head, $\mathrm{Y}_{23}=$ Type, $\mathrm{Y}_{24}=$ Repair Status, $\mathrm{Y}_{31}=$ Physical Health, $\mathrm{Y}_{32}=$ Disease Status, $\mathrm{Y}_{41}=$ Education, $\mathrm{X}_{11}=$ No of Physicians, $\mathrm{X}_{12}=$ No of Beds, $\mathrm{X}_{13}=$ Distance, $\mathrm{X}_{21}=$ Teacher-Student Ratio, $\mathrm{X}_{22}=$ Maximum Class Level, $\mathrm{X}_{23}=$ Teacher Education Level, $\mathrm{X}_{24}=$ Distance, $\mathrm{X}_{31}=$ Income, $\mathrm{X}_{32}=$ Expenditure, $\mathrm{X}_{33}=$ Comforts at home, $\mathrm{X}_{34}=$ Infrastructure, $\mathrm{X}_{41}=\mathrm{No}$ of Contacts, $\mathrm{X}_{42}=$ Frequency of Visiting.

Figure 4. The conceptual quality of life (QOL) model. 
around mining area). First study area was divided into a grid of 2 minutes (in longitude and latitude) interval. One village in each grid randomly selected. Then stratified sampling was employed in each sampling village by categorizing primary occupation of the head of household into seven groups as per Census classification; cultivators, agriculture labors, mining, manufacturing and processing, construction workers, trade and commerce, transportation and others. This was intended to reflect all social economic classes among the participants. A total of 232 samples were collected from 7 villages. Details of the samples collected from villages are given in Table 1.

\subsection{Socioeconomic Profile of the Study Area}

Population: The population figure of study area A as per the 2000 census report stands at 9043 . The population distribution under the age of 15 was approximately $42 \%$. Sex ratio is 1000 males: 880 Females. $84 \%$ families are nuclear type and the concept of joint family system is not prevalent. Religion and caste structure suggesting that the tribal are dominant (68.5\%) in most of the villages.

Literacy and Education: The literacy level in the villages surrounding the study area is very low. The literacy level in the surrounding villages is $32.7 \%$ the male literacy rate stands at $38.9 \%$ while that of female is $28.5 \%$. Out of a total population of 3145, only 649 males and 421 females were literate mostly at the primary level of education. The educational infrastructure available in these villages is merely to the primary levels. School teachers have not been provided at these government owned schools.

Health and Infrastructure: Health and sanitary conditions in the surrounding villages is rather poor. The facilities available to them from government and other agencies are also poor. Lack of basic awareness further aggravates the problem. Incidences of malaria is the highest amongst all reported diseases including Cold, Diarrhea, Measles, Anemia, Typhoid etc. Night blindness is a cause of concern not only in the slum but also in villages which are deep into the jungles. Health is a major problem where major mining operations are going on and liquor consumption rather high. In addition to the above health problems some seasonal diseases are also prevalent due lack of proper nutrition and deteriorated sanitary conditions. The existing position of health facilities is far from adequate. Block headquarters are far away from the villages. Some of the villages are being supported by Mine management provided mobile van which reaches village on irregular basis. There are some dispensaries available which are run by private mine owners. The villages nearby mine town are being taken care of facilities available in the township itself.

Economy: The economy of the area is heavily depended on forest and the mining activities. Casual labor looks to be the mainstay offered by the mines and Forest department. Agriculture is either neglected or continued at low profile. Quite naturally the economy neither has any focus nor any growth. Variations are quite apparent from village to village due to location variations.

\subsection{LISREL Analysis of the Proposed Model}

The above conceptual structural equation model (SEM) was executed using LISREL Ver. 7.2 software. The re-

Table 1. Details of the samples collected from seven villages.

\begin{tabular}{|c|c|c|c|c|c|c|c|c|c|}
\hline & Occupations & A & $\mathbf{B}$ & C & D & $\mathbf{E}$ & $\mathbf{F}$ & G & Total \\
\hline 1 & Cultivators & 6 & 4 & 1 & 3 & 1 & 1 & 2 & 18 \\
\hline 2 & Agriculture labours & 0 & 0 & 0 & 0 & 0 & 0 & 0 & 0 \\
\hline 3 & Live stock, forestry, fishing, etc. & 4 & 0 & 0 & 0 & 0 & 0 & 0 & 4 \\
\hline 4 & Mining and quarrying & 25 & 3 & 1 & 3 & 1 & 1 & 2 & 36 \\
\hline 5 & manufacturing and processing & 10 & 0 & 0 & 0 & 0 & 0 & 0 & 10 \\
\hline 6 & construction workers & 5 & 0 & 0 & 0 & 0 & 0 & 0 & 5 \\
\hline 7 & Trade and commerce workers & 21 & 2 & 1 & 3 & 1 & 1 & 2 & 31 \\
\hline 8 & $\begin{array}{c}\text { Transportation, storage and communication } \\
\text { workers }\end{array}$ & 3 & 0 & 0 & 0 & 0 & 0 & 0 & 3 \\
\hline \multirow[t]{2}{*}{9} & Other services & 94 & 9 & 2 & 10 & 2 & 2 & 6 & 125 \\
\hline & Total & 168 & 18 & 5 & 19 & 5 & 5 & 12 & 232 \\
\hline
\end{tabular}


sults of the run indicated that the proposed model was good. The $\chi^{2}$ statistic obtained for the model was 254.63 ( $\mathrm{df}=128, p<0.001$ ), which seemed to suggest not an adequate fit of the model. However, other indicators indicated much more favorable results. For example RMR $=0.051$; standardized RMR $=0.042$; GFI $=0.928$; adjusted GFI $=0.90$; $\mathrm{CFI}=0.981$. Table 2 shows the statistics obtained through the run.

The reason the $\chi^{2}$ statistic appeared not to support the model was likely caused by the large sample size $(\mathrm{N}=$ 231) used in the analysis. Since statistical power is a function of sample size, this means that the larger the sample size, the more likely it is that the $\chi^{2}$ statistic will suggest that the model be rejected. Therefore, in general, the $\chi^{2}$ statistic is not a good model fit indicator when the sample size is greater than 200 [48]. Although the $\chi^{2}$ statistic is reported here, the other statistical tests are more reliable, considering the large sample size used in this study. Table 3 shows the effects sample size has on the significance of $\chi^{2}$ values. As the sample size is reduced, the $\chi^{2}$ value becomes significant. The Critical $\mathrm{N}$ value indicates that the sample size would have to be reduced to 140 before a significant $\chi^{2}$ would be generated by hypothesized model.

The estimated standardized coefficients for the hypothesized model (shown in Table 4 and Figure 5) indicate that all of the paths in the model are significant at 0.05 level, with the exception of the following two paths:

1) From the social contacts to the personal education.

2) From housing to quality of life.

Nevertheless, the overall model fit is very strong and changes in the paths and removing non-significant path did not bring any model improvement.

\subsection{Latent Variable Interaction Modeling}

Latent Variable Scores (LVS) are individual scores on the latent variables in an estimated structural equation model. These can be obtained for any estimated single group LISREL model. Latent variables obtained from the structural equation model (Figure 5) were used for the latent variables interaction modeling. Interaction on de-

Table 2. Fit indices of the theoretical model.

\begin{tabular}{ccccccccc}
\hline$\chi^{2}$ & $\mathrm{df}$ & GFI & CFI & NFI & NNFI & RMR $^{*}$ & PGFI & CNv \\
\hline 254.6 & 128 & 0.92 & 0.981 & 0.96 & 0.96 & 0.04 & 0.50 & 142.61 \\
\hline
\end{tabular}

NOTE: ${ }^{*}=$ Standardised. $\quad \chi^{2}=$ Chi-Square, $\mathrm{df}=$ Degrees of freedom, GFI = Goodness Fit Index, CFI = Comparative Fit Index, NFI = Normed Fit Index, NNFI = Non-Normed Fit Index, RMR = Room Mean Square Residual, PNFI = Parsimony Normed Fit Index, CNv = Critical N Value.

Table 3. The effect of sample size on $\chi^{2}$ values and associated $\mathrm{P}$ values.

\begin{tabular}{cccccccccc}
\multicolumn{2}{r}{$\mathrm{N}=230$} & \multicolumn{2}{r}{$\mathrm{N}=200$} & \multicolumn{2}{r}{$\mathrm{N}=170$} & \multicolumn{2}{c}{$\mathrm{N}=140$} & \multicolumn{2}{c}{$\mathrm{N}=110$} \\
\hline$\chi^{2}$ & $p$ & $\chi^{2}$ & $p$ & $\chi^{2}$ & $p$ & $\chi^{2}$ & $p$ & $\chi^{2}$ & $p$ \\
254.63 & 0.000 & 221.27 & 0.000 & 187.91 & 0.0004 & 154.56 & 0.055 & 121.20 & 0.652 \\
\hline
\end{tabular}

Table 4. Estimated standardized path coefficients for the hypothesized model $(\mathrm{N}=232)$.

\begin{tabular}{|c|c|c|c|c|}
\hline & Housing & Health & Education & Quality of life \\
\hline Health facilities & - & $0.70^{*}$ & - & $0.18^{*}$ \\
\hline Educational facilities & - & - & $0.04^{*}$ & $0.13^{*}$ \\
\hline Wealth & $0.98^{*}$ & $0.68^{*}$ & $0.59^{*}$ & $0.65^{*}$ \\
\hline Social contacts & - & $0.07^{*}$ & 0.02 & $0.02^{*}$ \\
\hline Housing & - & - & - & 0.17 \\
\hline Health & - & - & $0.20^{*}$ & $0.12^{*}$ \\
\hline Education & - & - & - & $0.18^{*}$ \\
\hline $\mathrm{R}^{2}$ & 0.93 & 0.881 & 0.626 & 0.829 \\
\hline
\end{tabular}

Note: ${ }^{*}$ Indicates significance at 0.05 or better probability level. 


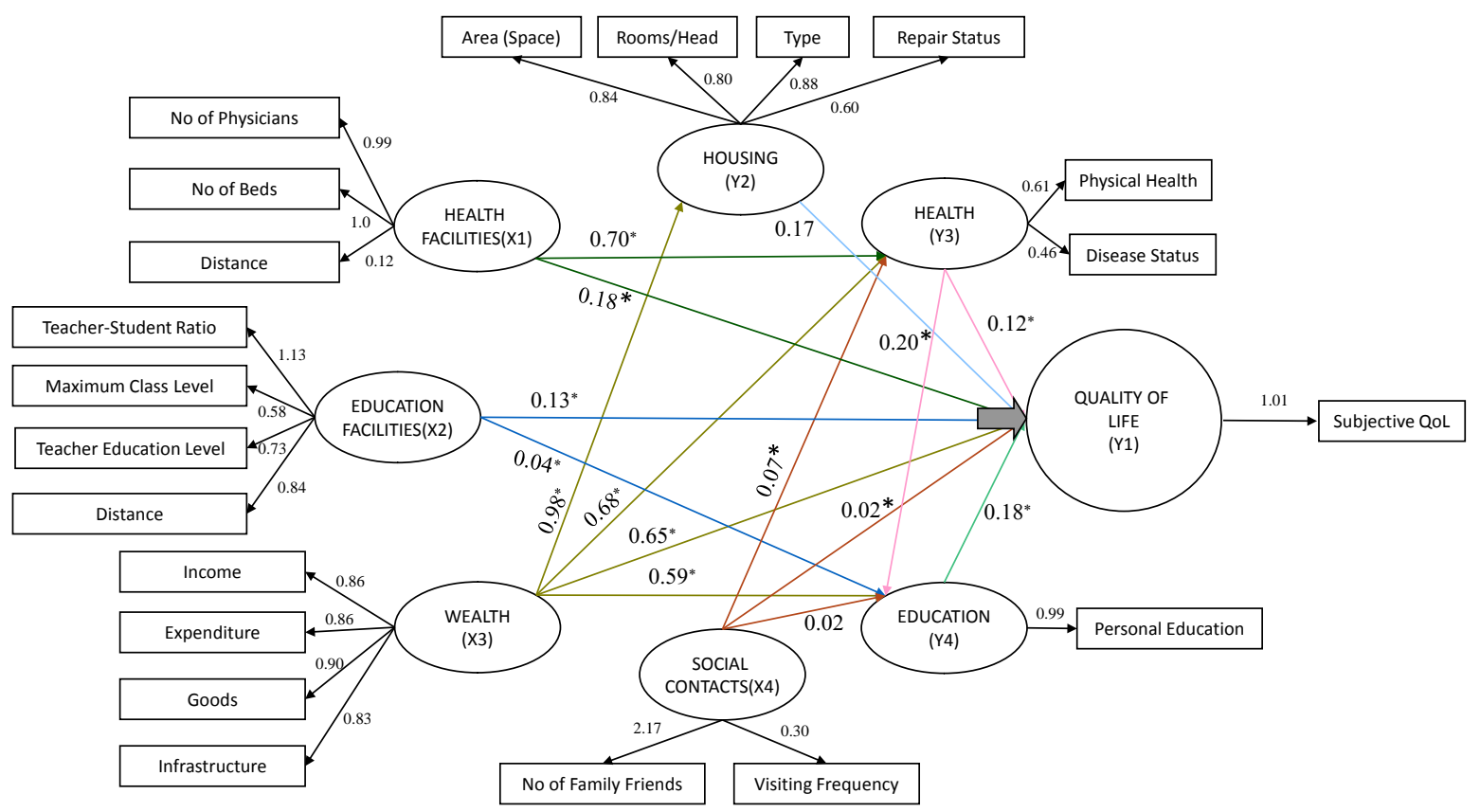

Figure 5. Quality of life model established.

pendent variable was done using all possible combinations of independent variables. For example regression on contacts was done using observed variables such as No of contacts $\left(\mathrm{x}_{41}\right)$ and Frequency of visiting $\left(\mathrm{x}_{42}\right)$ and also their interactions $\left(\mathrm{x}_{41} \times \mathrm{x}_{42}\right)$. These interactions improved the model $\mathrm{R}^{2}$ significantly in prediction of contacts, educational facilities and health facility. However, non-significant interactions were removed from the model. It can be observed from the interaction modeling equations that, all models have regression coefficient above 0.80 , except modeling equation for education whose regression coefficient was 0.626. This indicates that except education all other latent variables are well predicted by the respective observed variables. Error statistics for the predicted latent variables through latent variable modeling is show in Table 5.

Interaction between independent observed variables and exogenous latent variables

$$
\begin{aligned}
& \text { Wealth }=0.318+0.143^{\dagger} \times \mathrm{x}_{31}+0.138^{\dagger} \times \mathrm{x}_{32}+0.91^{\dagger} \times \mathrm{x}_{33}+0.279^{\dagger} \times \mathrm{x}_{34} \quad \mathrm{R}^{2}=0.989 \\
& \text { Contacts }=2.159^{\dagger}+1.045^{\dagger} \times \mathrm{x}_{41}-0.179 \times \mathrm{x}_{42}+0.017 \times \mathrm{x}_{41} \times \mathrm{x}_{42} \quad \mathrm{R}^{2}=0.885 \\
& \begin{aligned}
\mathrm{EFAC}= & 85.64^{\dagger}-1.2^{\dagger} \times \mathrm{x}_{21}+3.45^{\dagger} \times \mathrm{x}_{22}+14.68^{\dagger} \times \mathrm{x}_{23}-1.219^{\dagger} \times \mathrm{x}_{24}-0.121^{\dagger} \times \mathrm{x}_{21} \times \mathrm{x}_{22} \\
- & 0.52^{\dagger} \times \mathrm{x}_{22} \times \mathrm{x}_{23}-1.112^{\dagger} \times \mathrm{x}_{23} \times \mathrm{x}_{24}-0.004 \times \mathrm{x}_{23} \times \mathrm{x}_{24} \times \mathrm{x}_{21}+0.001^{\dagger} \times \mathrm{x}_{21} \times \mathrm{x}_{22} \times \mathrm{x}_{23} \times \mathrm{x}_{24} \\
\mathrm{R}^{2}= & 0.907
\end{aligned} \\
& \text { HFAC }=18.688^{\dagger}+0.121 \times \mathrm{x}_{11}+0.451^{\dagger} \times \mathrm{x}_{12}-0.673 \times \mathrm{x}_{13}+0.001^{\dagger} \times \mathrm{x}_{11} \times \mathrm{x}_{12} \times \mathrm{x}_{13} \quad \mathrm{R}^{2}=0.928
\end{aligned}
$$

where,

EFAC: educational facilities status, HFAC: health facilities status $\mathrm{x}_{11}$ : no of physicians, $\mathrm{x}_{12}$ : no of beds, $\mathrm{x}_{13}$ : distance, $\mathrm{x}_{21}$ : teacher-student ratio, $\mathrm{x}_{22}$ : maximum class level, $\mathrm{x}_{23}$ : teacher's education level, $\mathrm{x}_{24}$ : distance, $\mathrm{x}_{31}$ : per capita income, $\mathrm{x}_{32}$ : expenditure, $\mathrm{x}_{33}$ : conforts at home, $\mathrm{x}_{34}$ : infrastructure

${ }^{\dagger}$ indicates significant at 0.05 or better probability level

Interaction between exogenous latent variable and mediating latent variables

Education $=0.13^{\dagger} \times$ EFAC $^{\dagger}+0.65 \times$ Wealth $^{\dagger}+0.02 \times$ Contacts $+0.2 \times$ Health $+0.374 \quad \mathrm{R}^{2}=0.626$

$$
\begin{gathered}
\text { Health }=0.70^{\dagger} \times \text { HFAC }+0.68^{\dagger} \times \text { Wealth }+0.07^{\dagger} \times \text { Contacts }-0.281 \quad \mathrm{R}^{2}=0.881 \\
\text { Housing }=0.96^{\dagger} \times \text { Wealth }+0.041 \quad \mathrm{R}^{2}=0.93
\end{gathered}
$$

${ }^{\dagger}$ indicates significant at 0.05 or better probability level 
Table 5. Error statistics of the predicted latent variables using regression equation.

\begin{tabular}{ccccccccc}
\hline & Hfac & Efac & Wealth & Contacts & Housing & Health & Education & QOL \\
\hline R2 (Predicted Vs. Actual) & 0.82 & 0.96 & 1.00 & 0.94 & 0.96 & 0.89 & 0.65 & 0.91 \\
Mean error & 0.48 & -0.05 & -0.55 & 0.02 & -0.29 & -3.30 & -1.08 & 0.48 \\
Error variance & 0.44 & 6.34 & 2.32 & 0.959 & 6.51 & 16.60 & 1.89 & 18.50 \\
Mean square error & 0.67 & 6.33 & 2.61 & 0.955 & 6.57 & 27.42 & 3.07 & 18.66 \\
Mean absolute error & 8.97 & 2.04 & 1.26 & 0.80 & 1.96 & 3.67 & 1.22 & 3.18 \\
\hline
\end{tabular}

Interaction between exogenous latent variable, mediating latent variables and ultimate endogenous latent variable

$$
\begin{aligned}
\text { Quality of Life }= & 0.18^{\dagger} \times \text { HFAC }+0.04^{\dagger} \times \text { EFAC }+0.59^{\dagger} \times \text { Wealth }+0.02^{\dagger} \times \text { Contacts } \\
& +0.17 \times \text { Housing }+0.12^{\dagger} \times \text { Health }+0.18^{\dagger} \times \text { Education }+0.171^{\dagger} \quad \mathrm{R}^{2}=0.829 .
\end{aligned}
$$

${ }^{\dagger}$ indicates significant at 0.05 or better probability level

\subsection{Impact Analysis}

Impact on the quality of life due to direct income was evaluated by recalculating the monthly income (Independent manifest variable for the wealth construct) of the families after subtracting the income derived from mining. Modified monthly income had taken as an input to the latent variable model (LVM) derived in the previous section to calculate the quality of life. The percentage of change in the quality of life (village wise) has been shown in Figure 6. This shows the impact on the people who directly draw income from mining company in the form of their monthly salaries. However, the benefits that may be received from the mining company after mine closure is not considered in the evaluation the impact.

To derive the impact of loss of indirect income from mining, it was assumed that $50 \%$ of the income will be lost due to mine closure. Impact was evaluated by recalculating the monthly income of the families by subtracting the $50 \%$ of the indirect mining depended income. Similarly, modified monthly income was taken as an input to the latent variable model (LVM) derived in the previous section to calculate the quality of life. Figure 7 shows the impact on the people who indirectly depend on mining for their monthly income. For example: businessmen, daily labors and temporary workers in the mines, domestic workers etc. The percentage of change in the quality of life (village wise) has been shown in Figure 7.

Impact of health facilities on QOL is derived by replacing health facilities variable values (No. of physicians, No. of beds and distance) by the health facilities that will remain after closure (assumed that government provided health facilities and other private health facilities will remain after closure). Figure 8 suggests that closing of health facilities have significant impact similar to impact due to loss of income.

Impact of education facilities on QOL is derived by replacing the values of variables affecting educational facilities (student-teacher ratio, maximum class level, teacher's education level, distance) by the educational facilities that will remain after closure (assumed that government provided educational facilities and other private educational facilities will remain after closure also). From Figure 9 it can be observed that the impact of educational facilities on the quality of life is not as significant as heath facilities and income.

Impact on QOL due to emigration was derived by subtracting the number of migrated family friends from present family friends. Impact due loss of contact is not as much as impact due to other parameters. Figure 10 shows the impact on QOL of the communities due to emigration.

\section{Discussion}

The findings of this study reveals that mine closure has a significant impact on the quality of life of the nearby comminutes. This is established through structural equation modeling and latent variable modeling based on previous research which had demonstrated that satisfaction with life in general could be predicted by objective life status. Structural equation modeling was used to propose and test a good fit model for evaluating impacts of mine closure on the neighboring communities. This was done by examining the effects of income, health and 


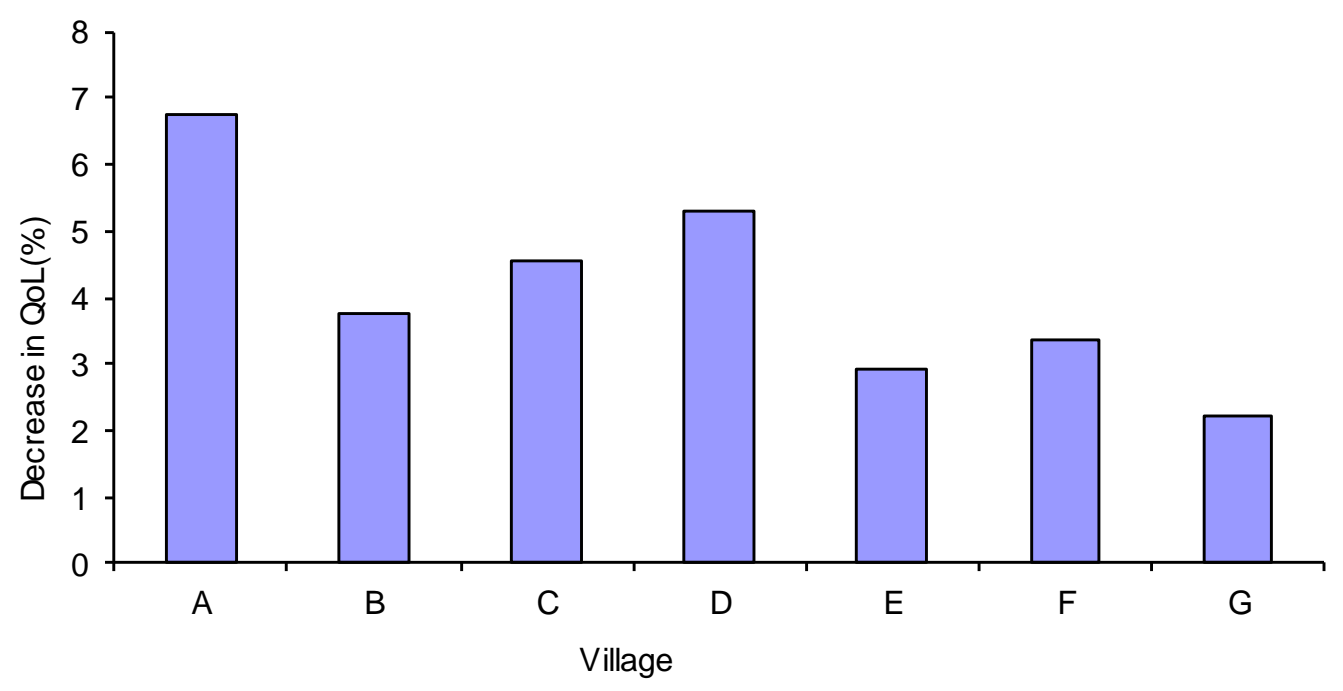

Figure 6. Impact due to loss of direct income on the QOL of the communities.

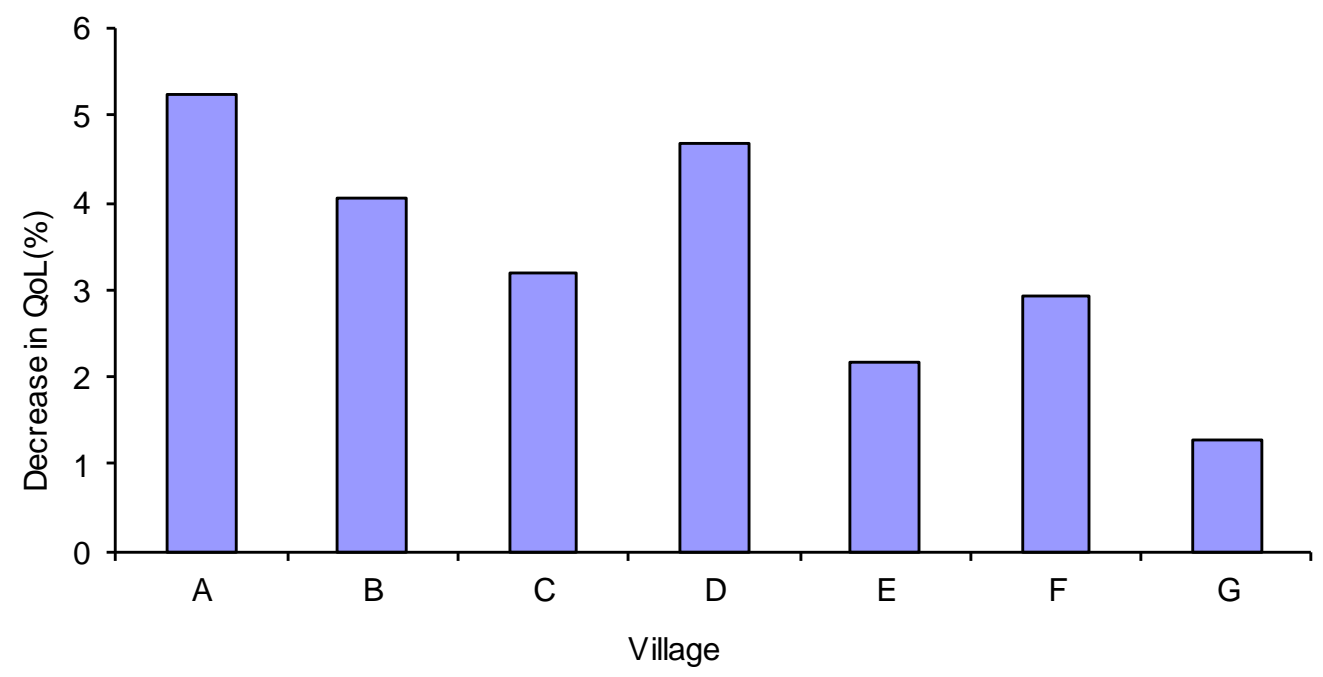

Figure 7. Impact due to loss of indirect income on the QOL of the communities.

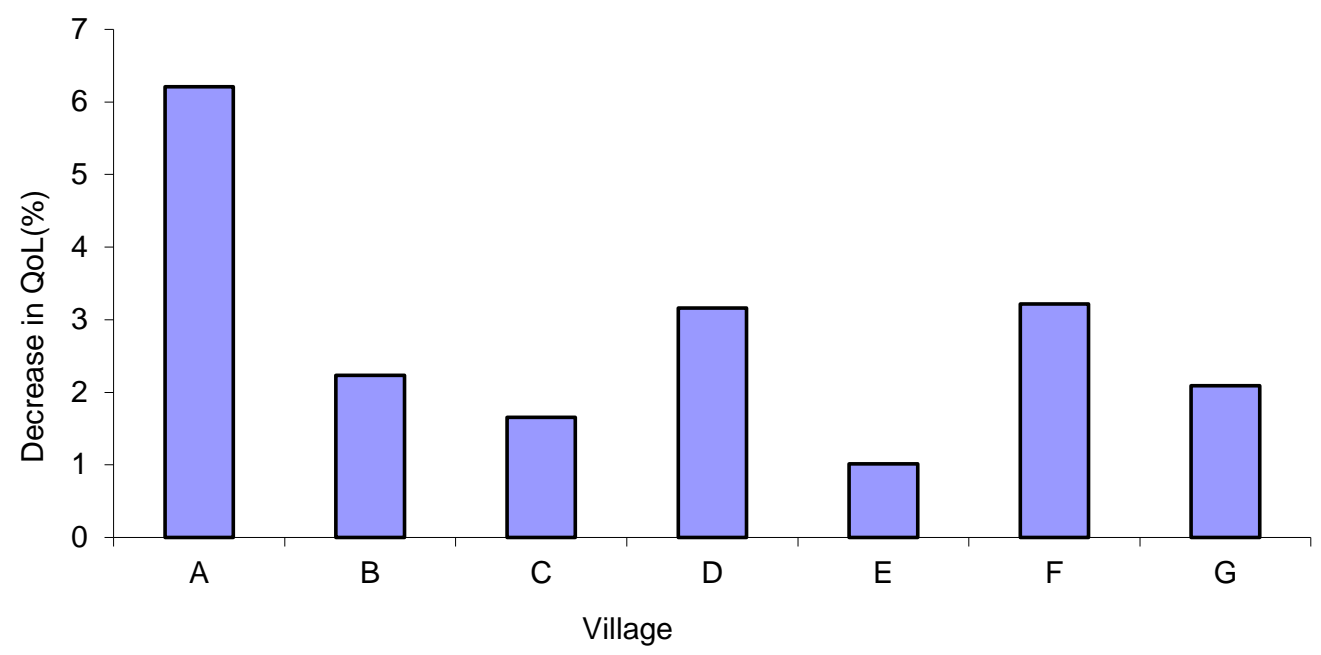

Figure 8. Impact due to closing of health facilities on the QOL of the communities. 


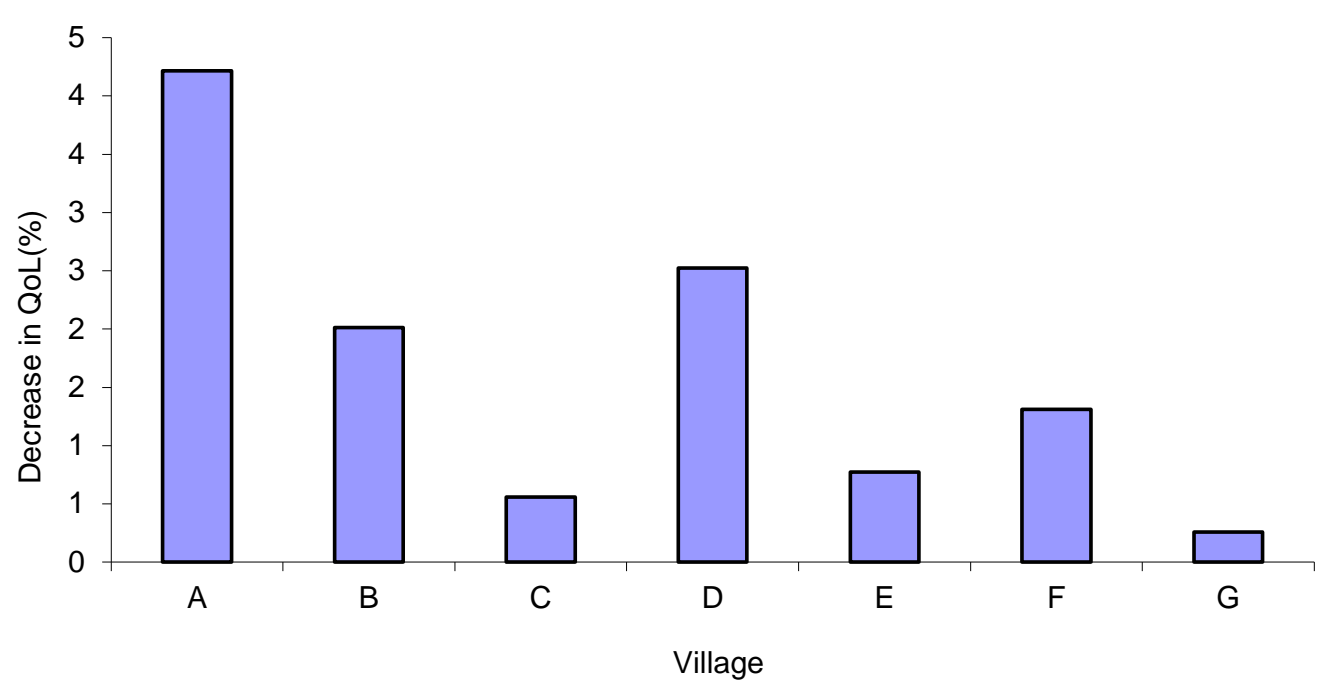

Figure 9. Impact due to closing of educational facilities on the QOL of the communities.

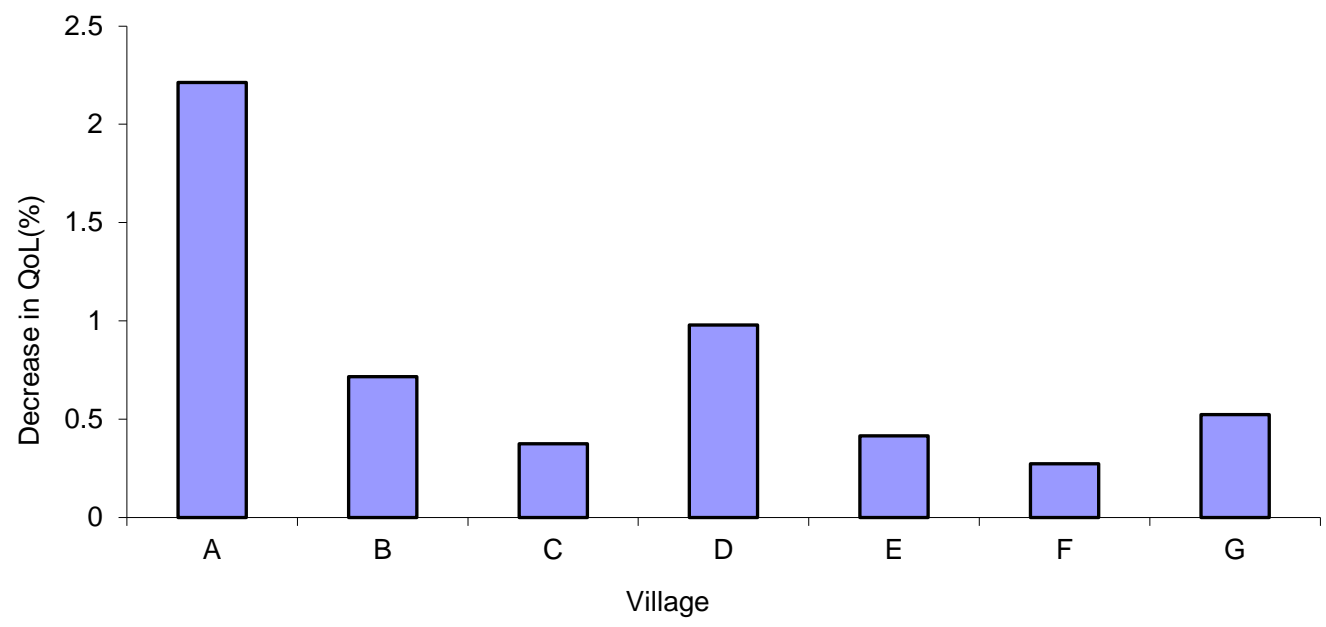

Figure 10. Impact due to loss of contacts (emigration) on the QOL of the communities.

education facilities, inter-family relations on housing, health, education and finally on quality of life of communities living nearby mining area.

The findings from the present study establish that QOL is significantly affected by certain mining dependent parameters such as income, health and educational facilities, social contacts, etc. It was found that personal wealth is a very important element in the maintenance of subjective quality of life. Wealth resources has significant contribution in predicting QOL $(\gamma=0.65, p<0.06)$ by both direct and indirect ways. The structural model also reveal that wealth has indirect positive causal effect on the QOL though housing $(\gamma=0.98, p<0.05)$, health $(\gamma=0.68, p<0.05)$, education $(\gamma=0.59, p<0.05)$. This is in conformity to the general statement that people with more wealth have higher sense of wellbeing.

Conforming to the findings of Smith [49] and Ettner [50], the developed model shows positive correlation between health and economic resources $(\gamma=0.68, p<0.05)$. The present model establishes that income, expenditure, comforts at home and facilities are proxies for wealth and have positive contribution to health. Health facilities have positive significant role $(\gamma=0.7, p<0.05)$ in improving health of the communities and family health has significant contribution in improving quality of life, hence health facilities directly as well as indirectly brings a significant change in quality of life. Number of physicians and number beds are appear to be good predictors of health facilities than distance from the community, possibly because people prefer better health facilities even at a greater distance. 
The " $\gamma$ " and " $p$ " values obtained to assess the impacts of educational facilities on personal education reveal that education facilities have little influence on quality of life. Most of the villages in the study area have elementary schools and high schools which are maintained by the government. However, most of the people are illiterates due to lack of educational awareness. This may be the reason for little influence of education facilities on education. Teacher-student ratio, education level of teacher and class size are emerged as good predictors of educational facilities than the distance of the educational facilities from the residence.

The developed model suggests that interfamily relations have significant contribution to the quality of life $(\gamma=$ $0.02, p<0.05$ ). These effects are significant both direct and indirect paths through health. However, it is well documented that more interaction with other families and helping each other improves the QOL. Interfamily relations does not have significant influence on the education. This is attributed to lack of educational awareness amongst families.

\section{Conclusions}

It is evident from the study that exploring alternate economic arrangements should be the primary concern during mine closure planning in the study areas. From the model it was noticed that satisfaction with life in general was confirmed to be significantly predicted (at 0.05 significance level) by objective factors such as personal income, health, education, service and facilities, etc. A linear relationship was revealed between objective quality of life status and subjective quality of life satisfaction. The results of this study suggest that identification of proactive factors that influence the QOL of the communities nearby mining area provide useful information for mine closure planners to minimize the post closure social impacts.

As noticed earlier that quality of life associated with many factors. In the present study the major factors which were directly influenced by mine closure in previous case studies were considered. According to the literature, the subjective response of the QOL/Wellbeing depends on the nature of neighborhood environment, so the present model will be used only to predict the social impacts of two mines from which data has been collected. In measuring health status, long term illness or diseases and physical disabilities were considered. Short term illness and psychological health which change with time were not considered in the present study. Although some factors were addressed in the literature as potential factors of QOL, they were not considered because they were beyond the scope of the study. This study has assumed that no significant physical or chemical environmental problem would exist after mine closure.

\section{References}

[1] Sarkar, S.K. and Sarkar, S. (1996) State of Environmental and Development in Indian Coal Fields: Coal Fields in West Bengal. Oxford \& IBH Publishing, New Delhi.

[2] Andrews-Speed, P., Guo, M., Bingjia, S. and Chenglin, L. (2005) Economic Responses to the Closure of Small-Scale Coal Mines in Chongqing, China. Resources Policy, 30, 39-54. http://dx.doi.org/10.1016/j.resourpol.2004.12.002

[3] Kahn, J.R., Franceschi, D., Curi, A. and Vale, E. (2001) Economic and Financial Aspects of Mine Closure. Natural Resources Forum, 25, 265-274. http://dx.doi.org/10.1111/j.1477-8947.2001.tb00768.x

[4] Redgwell, C. (1992) Abandonment and Reclamation Obligations in the United Kingdom. Journal of Energy and Natural Resources Law, 10, 59-86.

[5] Kuhne, G. (1992) Abandonment and Reclamation of Energy Sites and Facilities: Germany. Journal of Energy and Natural Resources Law, 10, 4-20.

[6] Brook, D. (1994) Reclamation of Abandoned Underground Mines in the United States. Mineral Planning, 61, 21-26.

[7] Meyer, P.B., Williams, R.H. and Young, K.R. (1995) Contaminated Land-Reclamation, Redevelopment and Reuse in the United States and the European Union. Edward Elgar, Cheltenham.

[8] Finsterbusch, K. (1980) Understanding Social Impacts. Saga Publication, California.

[9] Michael, H. and Maria, S. (2003) Mine Closure and Its Impact on the Community: Five Years after Mine Closure in Romania, Russia and Ukraine. World Bank Policy Research Working Paper Series, 3083.

[10] Chattopadhyay, S.S. (2001) Theratholes of Raniganj. Frontline Magazine, Vol. 18. http://www.frontline.in/static/html/fl1824/18240500.htm

[11] Berkman, L.F. and Breslow, L. (1983) Health and Ways of Living: The Alameda Country Study. Oxford University Press, New York. 
[12] Raphael, D., Renwick, R., Brown, I. and Rootman, I. (1996) Quality of Life Indicators and Health: Current Status and Emerging Conceptions. Social Indicators Research, 39, 65-88. http://dx.doi.org/10.1007/BF00300833

[13] Smith, A.E. (2000) Quality of Life: A Review. Education and Aging, 15, 419-435.

[14] Derrett, S., Paul, C. and Morris, J. (1999) Waiting for Elective Surgery: Effects on Health-Related Quality of Life. International Journal for Quality in Health Care, 11, 47-57. http://dx.doi.org/10.1093/intqhc/11.1.47

[15] Gill, T. and Feinstein, A.A. (1994) Critical Appraisal of the Quality-of-Life Measurements. Journal of American Medical Association, 272, 619-626. http://dx.doi.org/10.1001/jama.1994.03520080061045

[16] Fabian, E.S. (1990) Quality of Life: A Review of Theory and Practice Implications for Individuals with Long-Term Mental Illness. Rehabilitation Psychology, 35, 161-169. http://dx.doi.org/10.1037/h0079059

[17] Packer, T., Race, K.E.H. and Hotch, D.F. (1994) Focus Groups: A Tool for Consumer-Based Program Evaluation in Rehabilitation Agency Settings. Journal of Rehabilitation, 60, 30-33.

[18] Jones, J., Dagnan, D., Trower, P. and Ruddick, L. (1996) People with Learning Disabilities Living in Community-Based Homes: The Relationship of Quality of Life with Age and Disability. International Journal of Rehabilitation Research, 19, 219-227. http://dx.doi.org/10.1097/00004356-199609000-00003

[19] Linda, S. and Robert, G. (2005) Sustainable Transportation and Quality of Life. Journal of Transport Geography, 13, 59-69. http://dx.doi.org/10.1016/j.jtrangeo.2004.11.003

[20] Michael, K., Monika, K.S. and Wilfried, L. (2005) Outcome and Quality of Life in Medicine: A Conceptual Framework to Put Quality of Life Research into Practice. Urologic Oncology Seminars and Original Investigations, 23, $186-$ 192. http://dx.doi.org/10.1016/j.urolonc.2005.03.002

[21] Tankova, T., Galina, D. and Dragomir, K. (2005) Education and Quality of Life in Diabetic Patients. Patient Education and Counseling, 53, 285-290. http://dx.doi.org/10.1016/j.pec.2003.09.013

[22] Robert, W.M. (2003) Understanding Environmental Quality through Quality of Life Studies: The 2001 DAS and Its Use of Subjective and Objective Indicators. Landscape and Urban Planning, 65, 73-83. http://dx.doi.org/10.1016/S0169-2046(02)00239-6

[23] Felce, D. (1997) Defining and Applying the Concept of Quality of Life. Journal of Intellectual Disability Research, 41, 126-135. http://dx.doi.org/10.1111/j.1365-2788.1997.tb00689.x

[24] Hanestad, B. (1990) Errors of Measurement Affecting the Reliability and Validity of Data Acquired from Self-Assessed Quality of Life. Scandinavian Journal of Caring Sciences, 30, 1349-1359.

[25] John, M. and Catherine, E.R. (2005) Education, Learned Effectiveness and Health. London Review of Education, 3, 205-220. http://dx.doi.org/10.1080/14748460500372366

[26] Azapagic, A. (2004) Developing a Framework for Sustainable Development Indicators for the Mining and Minerals Industry. Journal of Cleaner Production, 12, 639-662. http://dx.doi.org/10.1016/S0959-6526(03)00075-1

[27] Scott, P. (2005) Mining and Poverty Reduction: Transforming Rhetoric into Reality. Journal of Cleaner Production, 14, 376-387.

[28] Figueroa, B.E. and Calfucura, T.E. (2003) Growth and Green Income: Evidence from Mining in Chile. Resources Policy, 29, 165-173. http://dx.doi.org/10.1016/j.resourpol.2004.08.003

[29] Patricio, A. (2001) Impacts and Development in Local Economies Based on Mining: The Case of the Chilean II Region. Resources Policy, 27, 119-134. http://dx.doi.org/10.1016/S0301-4207(01)00013-7

[30] Benjamin, N.A. (2001) Ghana’s Mining Sector: Its Contribution to the National Economy. Resources Policy, 27, 61-75. http://dx.doi.org/10.1016/S0301-4207(00)00042-8

[31] George, S.D. and Weitz, B.A. (1997) Comparative Urban Social Indicators: Problem and Prospects. Policy Sciences, 8, 423-435.

[32] Mirinigoff, M.L. (1996) The Growing Gap between Standard Economic Indicators and the Nation’s Social Health. Challenge, 39, 17-22.

[33] Pacione, M. (1982) The Use of Objective and Subjective Measures of Quality of Life in Human Geography. Progress in Human Geography, 6, 495-514.

[34] Rogerson, R.J., Findlay, A.M., Morris, A.S. and Coombes, M.G. (1989) Indicators of Quality of Life: Some Methodological Issues. Environment and Planning, 21, 1655-1666. http://dx.doi.org/10.1068/a211655

[35] Abrams, M. (1977) Social Indicators and Social Equity. New Society, 22, 454-455.

[36] Felce, D. and Perry, J. (1995) Quality of Life: Its Definition and Measurement. Research in Developmental Disabilities, 16, 51-74. http://dx.doi.org/10.1016/0891-4222(94)00028-8

[37] Cummins, R.A. (2000) Personal Income and Subjective Wellbeing: A Review. Journal of Happiness Studies, 1, 133158. http://dx.doi.org/10.1023/A:1010079728426 
[38] Beckie, T.M. and Hayduk, L.A. (1977) Measuring Quality of Life. Social Indicators Research, 42, 21-39. http://dx.doi.org/10.1023/A:1006881931793

[39] Fakhoury, W.K.H. and Priebe, S. (2002) Subjective Quality of Life: It's Association with Other Constructs. International Review of Psychiatry, 14, 219-224. http://dx.doi.org/10.1080/09540260220144957

[40] Lee, E. (2002) Estimation of Quality of Life Korean Cities. Proceedings of the 6th Russian-Korean International Symposium on Science and Technology (KORUS), Novosibirsk, 24-30 June 2002, 93-95.

[41] Singh, P. and Chand, R. (2000) Quality of Life Approach for Identification of Poor. Journal of Rural Development, 19, 27-68.

[42] Linga, N. and Subramanya, N. (2005) Assessing Quality of Life in a Mining Region. Economic Political Weekly, $72-$ 78.

[43] Poston, D., Turnbull, A., Park, J., Hasheem, M., Jane, M. and Wang, M. (2003) Family Quality of Life: A Qualitative Inquiry. Mental Retardation, 41, 313-328. http://dx.doi.org/10.1352/0047-6765(2003)41<313:FQOLAQ>2.0.CO;2

[44] Ontario Social Development Council (1997) Quality of Life in Ontario. Ontario Social Development Council, Ontario.

[45] Joreskog, K.G. (2000) Latent Variable Scores and Their Uses. Scientific Software International, Inc., Lincolnwood.

[46] Schumacker, R.E. (2002) Latent Variable Interaction Modeling. Structural Equation Modeling, 9, 40-54. http://dx.doi.org/10.1207/S15328007SEM0901_3

[47] Bollen, K.A. and Long, J.S., Eds. (1993) Testing Structural Equation Models. SAGE Publications, London.

[48] Bagozzi, R.P. and Youjae, Y. (1988) On the Evaluation of Structural Equation Models. Journal of the Academy of Marketing Science, 16, 74-94. http://dx.doi.org/10.1007/BF02723327

[49] Smith, J.P. (1999) Health Bodies and Thick Wallets: The Dual Relation between Health and Economic Status. Journal of Economic Perspectives, 13, 145-166. http://dx.doi.org/10.1257/jep.13.2.145

[50] Ettner, S. (1996) New Evidence on the Relationship between SES and Health. Journal of Health Economics, 15, 67-85. http://dx.doi.org/10.1016/0167-6296(95)00032-1 
Scientific Research Publishing (SCIRP) is one of the largest Open Access journal publishers. It is currently publishing more than 200 open access, online, peer-reviewed journals covering a wide range of academic disciplines. SCIRP serves the worldwide academic communities and contributes to the progress and application of science with its publication.

Other selected journals from SCIRP are listed as below. Submit your manuscript to us via either submit@scirp.org or Online Submission Portal.
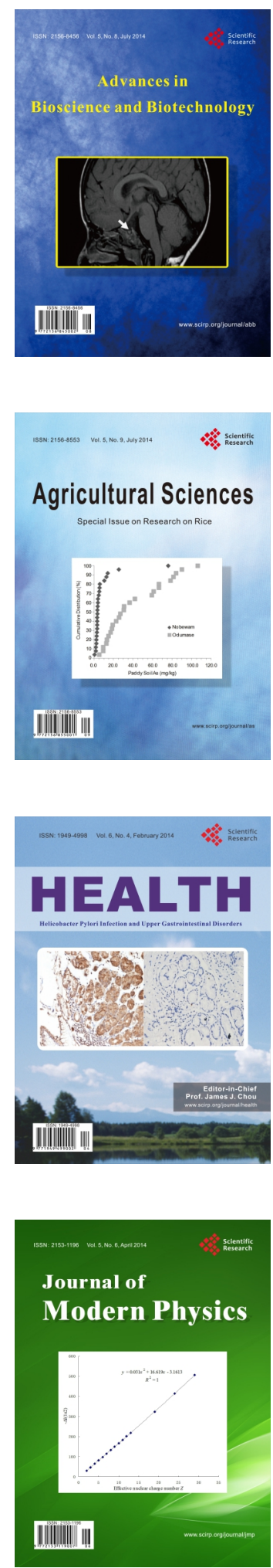
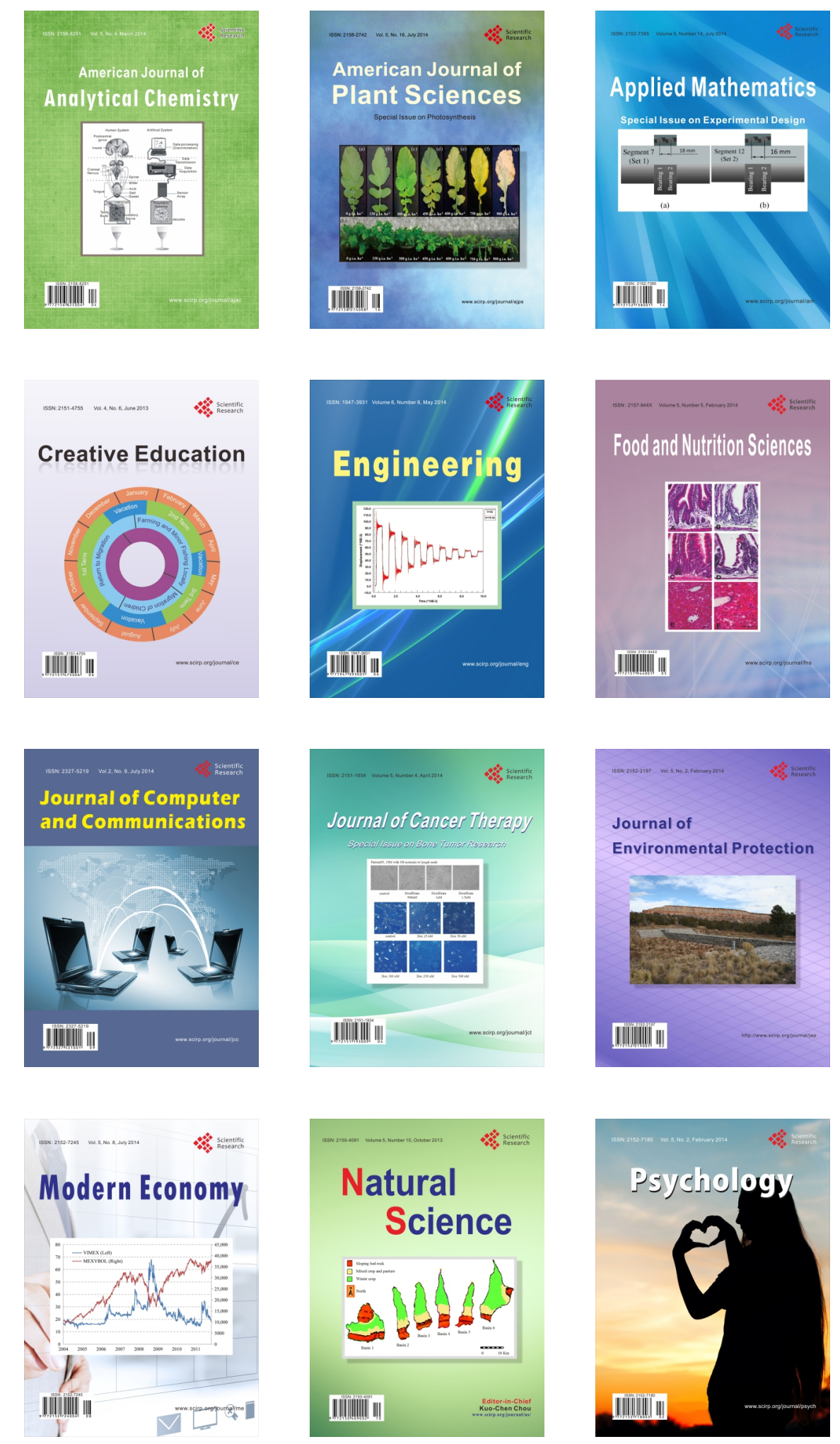